
UNDER CONTRACT DE-AC02-76-CHO-3073

PPPL-2826

UC-427

WEAK-AND STRONG-TURBULENCE REGIMES OF THE HASEGAWA-MIMA EQUATION

BY

M. OTTAVIANI AND J. KROMMES

February 1992
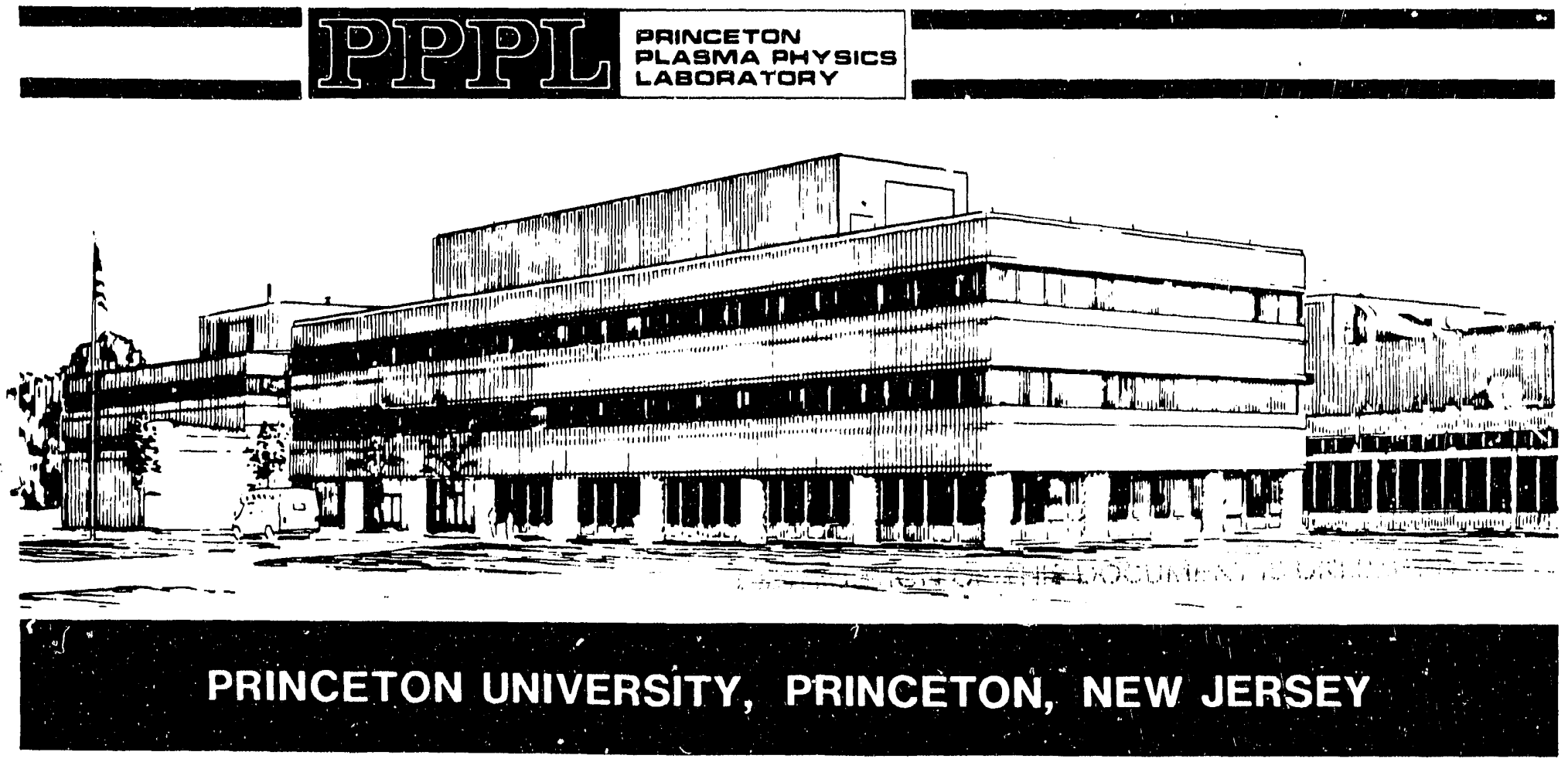


\section{Weak- and strong-turbulence regimes of the Hasegawa-Mima equation}

Maurizio Ottaviani(a) and John A. Krommes

Plasma Physics Laboratory, Princeton University, P.O. Box 451, Princeton, NJ 08543

A Kolmogorov-type analysis of the energy-and enstrophy-cascading ranges of the forced Hasegawa-Mima equation allows one to derive a criterion for the threshold of the transition between the weak turbulence and the strong turbulence regimes. It is found that, due to the inverse energy cascade, the large-scale portion of the inertial range is in the strong turbulence regime in the limit of infinite Reynolds-like numbers.

PACS numbers: 52.35.Ra, 47.25.-c

Among the tools employed to analyze the various reduced models of plasma turbulence, the weak turbulence approximation [1] (WTA) is perhaps the most popular. Formally, the WTA for a given nonlinear model is introduced as an expansion in terms of the magnitude of the coupling coefficients [2] or as a multiple-time-scale expansion [3!. The physical WTA expansion parameter, however, turns out to be a dimensionless quantity representing the ratio of the rate of energy injection to some measure of wave dispersion. For example, if the turbulence model involves just a single scalar field (as in the case of the

(a) Present address: JET Joint Undertaking, Abingdon, Oxfordshire OX14 3EA, England.

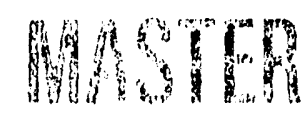


two-dimensional Navier-Stokes equation or the Hasegawa-Mima equation [4], the proper WTA expansion parameter $\epsilon_{W T}$ is

$$
\epsilon W T \doteq \gamma_{k} / \Delta \omega_{k}
$$

where $\gamma_{k}$ is the growth rate of a given instability as a function of the wavenumber $k$ and $\Delta \omega_{k} \doteq \omega_{k}-k \cdot v_{g, k}$, with $\omega_{k}$ being the wave frequency and $v_{g, k}$ being the group velocity, is a measure of wave dispersion.

It is generally assumed that the condition that $\epsilon_{W T}$ is somewhat smaller than one is sufficient for the applicability of the WTA. Moreover, in many applications the spectrum of unstable modes, driven by $\gamma_{k}$, is localized to scales substantially smaller than the size of the system. One typically considers a region in wavenumber space around $k_{\perp} \rho_{i} \approx 1$, where $\rho_{i}$ is the ion gyroradius. Since the long-wavelength modes are stable or only weakly unstable, one generally concludes that large-scale turbulent dynamics are appropriately described by weak turbulence equations.

Implicit to this viewpoint is the assumption that the shape of the turbulent spectrum somehow resembles the profile of the instability growth rate. Therefore, in the wavenumber region where $\epsilon_{\mathrm{WT}}$ is significantly smaller than unity nonlinear interactions are assumed to be small compared to wave dispersion and wavelike phenomena are considered to be dominant.

That this line of thought is at least questionable can be understood by noting that the primary effect of nonlinear interactions, which are generally conservative, is to transfer 
energy to scales different from those into which it is injected. Therefore, even in regions of negligible growth rate the fluctuation level can be so high that the dynamics are dominated by nonlinearity. The conclusion is that in order to assess the validity of the weak turbulence approach one must perform a more detailed analysis of the nonlinear dynamics.

In this letter we carry out such analysis for a specific model, the forced HasegawaMima (HM) equation [4], the paradigm for a large class of plasma turbulerice models. The main conclusion will be that large scales are always in the regime of strong turbulence in the limit of infinite Reynolds-like numbers.

Upon employing the usual normalizations (lengths normalized to $\rho_{\mathrm{s}}$, where $\rho_{\mathrm{s}} \doteq$ $c_{\mathrm{s}} / \omega_{\mathrm{ci}}, c_{\mathrm{s}} \doteq\left(T_{e} / m_{i}\right)^{1 / 2}$, and $\omega_{\mathrm{ci}} \doteq e B / m_{i} c$; times normalized to $L_{n} / c_{\mathbf{s}}$, where $L_{n}$ is the density scale length), the forced Hasegawa-Mima equation can be written as

$$
\partial_{t}\left(1-\nabla^{2}\right) \Phi+\partial_{y} \Phi+\hat{\gamma} \Phi+V_{E} \cdot \nabla\left(-\nabla^{2} \Phi\right)=-\nu_{L} \nabla^{p_{L}} \Phi-\nu_{S} \nabla^{p_{S}} \Phi
$$

where $\bar{\gamma}$ is a linear growth-rate operator associated with the energy injection and the righthand side represents phenomenological dissipation terms associated with large-scale and small-scale damping coefficients [(hyper-)viscosities] $\nu_{L}$ and $\nu_{\mathrm{S}}$ respectively. Also, $V_{E}$ is the $E \times B$ velocity: for any scalar field $\psi, V_{E} \cdot \nabla \psi=\partial_{x} \Phi \partial_{y} \psi-\partial_{y} \Phi \partial_{x} \psi$.

In the following it is assumed that $\gamma_{k}$ vanishes outside a small band of width $\Delta k_{f}$ centered around the forcing wavenumber $k_{f}$. Then the model possesses three dimensionless control parameters: two Reynolds-like numbers, inversely proportional to $\nu_{\mathrm{S}}$ and $\nu_{\mathrm{L}}$; and the weak turbulence parameter $\epsilon_{\mathrm{WT}}$. In the limit $\nu_{\mathrm{S}} \rightarrow 0, \nu_{\mathrm{L}} \rightarrow 0$, the inertial ranges 
virtually extend from zero wavenumber to infinite wavenumber. Then, varying eWT allows one to pass from regimes of fully developed weak turbulence to regimes of fully developed strong turbulence. Note that, depending on the value of $\epsilon_{\mathrm{W} T}$, different regimes may occur in different wavenumber ranges.

The analysis of the turbulent cascade is made difficult by the fact that the present model is not scale-invariant due to the operator $1-\nabla^{2}$. In addition, the presence of waves makes the spectrum anisotropic. These difficulties can be circumvented in the strong turbulence (ST) regime. Indeed, in the ST regime wave effects are negligible and one can drop the wave operator altogether. In addition, one can break the wavenumber space into two regions: $k \ll 1$ and $k \gg 1$. In each of these regions the dynamics are described by scale-invariant equations. A Kolmogorov-type analysis can then be carried out separately in the two regions and the spectra connected afterwards.

Let us first consider the case $: \ll 1$. In the absence of forcing and damping, the Hasegawa-Mima equation reduces to

$$
\partial_{t}+V_{E} \cdot \nabla\left(-\nabla^{2} \Phi\right)=0
$$

The scale transformation $(x, y) \rightarrow \lambda(x, y), t \rightarrow \tau t$ leaves Eq. (1) unchanged provided that $\Phi \rightarrow\left(\lambda^{4} / \tau\right) \Phi$. Therefore the intrinsic dimensions of the field $\Phi$ associated with scale invariance in the $k \ll 1$ regime are

$$
[\Phi] \sim[\text { length }]^{4}[\text { time }]^{-1} \quad(k \ll 1) .
$$


The two invariants of the full Hasegawa-Mima equation reduce to $E=\sum_{k}\left|\Phi_{k}\right|^{2}$ (energy) and $Z=\sum_{k} k^{2}\left|\Phi_{k}\right|^{2}$ (enstrophy). As usual, energy cascades to low $k$ while enstrophy cascades to high $k$ in the limit of infinite Reynolds numbers. In the energy-cascading range the rate of energy transfer $\epsilon$ across wavenumber space is constant. Dimensionally, upon using Eq. (2) one finds $[\epsilon] \sim[\text { length }]^{8}[\text { time }]^{-3}$. Then the energy-transfer timescale (turnover time) at wavenumber $k$ is given by

$$
\tau_{k}^{(E)} \sim \epsilon^{-1 / 3} k^{-8 / 3}
$$

Similarly one obtains $\tau_{k}^{(Z)} \sim \eta^{-1 / 3} k^{-2}$ in the enstrophy-cascading range, where $\eta$ is the rate of enstrophy transfer. Upon defining the potential spectrum $E_{\phi}(k)$ such that $\int_{0}^{\infty} d k E_{\phi}(k)=\sum_{k}\left|\Phi_{k}\right|^{2}$ and using again Eq. (2), one obtains

$$
E_{\phi}(k) \sim \begin{cases}C_{\mathrm{K}} \epsilon^{2 / 3} k^{-11 / 3} & \left(k<k_{f}\right) \\ C_{\mathrm{K}} \eta^{2 / 3} k^{-5} & \left(k>k_{\mathrm{f}}\right)\end{cases}
$$

In the opposite case $k \gg 1$ the Hasegawa-Mima equation reduces to the two-dimensional Navier-Stokes equation. Then invariants are the usual energy $E=\sum_{k} k^{2}\left|\Phi_{k}\right|^{2}$ and enstrophy $Z=\sum_{k} k^{4}\left|\Phi_{k}\right|^{2}$. The potential has the dimensions of a stream function and one recovers the well known expressions for the turnover times $[5]: \tau_{k}^{(E)} \sim \epsilon^{-1 / 3} k^{-2 / 3}$ and $\tau_{k}^{(Z)} \sim \eta^{-1 / 3}$. Still, the same dependence (3) on $k$ is obtained. Indeed, Eqs. (3) yield the usual Kolmogorov expressions when written in terms of the energy spectral density.

One can recognize that $\epsilon$ and $\eta$ are the rate of transfer of the invariants of the full Hasegawa-Mima equation $E=\sum_{k}\left(1+k^{2}\right)\left|\Phi_{k}\right|^{2}$ and $Z=\sum_{k} k^{2}\left(1+k^{2}\right)\left|\Phi_{k}\right|^{2}$. Then it is natural to assume that the spectral functions join smoothly at $k_{\mathrm{f}} \approx 1$, thus implying the same value of the Kolmogorov constant $C_{\mathrm{K}}$ throughout the whole $k$ space. 
The validity of the ST approximation require : that energy transfer due to nonlinearity dominates over wave dispersion. Since the appropriate measure of the rate of energy transfer in wavenumber space is the local turnover time $\tau_{k}$, the ST approximation is valid when

$$
\frac{1}{\tau_{k} \Delta \omega_{k}}>1
$$

Upon using the limiting expressions $\Delta \omega_{k} \sim k_{y} k^{2} \sim k^{3}$ and $\Delta \omega_{k} \sim k_{y} / k^{2} \sim k^{-1}$ for $k \ll 1$ and $k \gg 1$ respectively, one can evaluate the conditions given in Eq. (4). In the longwavelength limit one finds that $1 /\left(\tau_{k} \Delta \omega_{k}\right) \sim \epsilon^{1 / 3} k^{-1 / 3}$. Therefore long wavelengths are always found in the ST regime in the limit of zero large-scale dissipation (infinite large-scale Reynolds number).

The behavior of $1 /\left(\tau_{k} \Delta \omega_{k}\right)$ as a function of $k$ is depicted in Figs. 1 and 2 for $k_{f}<1$ and $k_{f}>1$ respectively. For each $k$, the criterion for the transition from WT to ST depends on the forcing. In any case, one can see from Figs. 1 and 2 that the wavenumber region that first enters the WT regime as the forcing is reduced is $k \approx 1$. The transition criterion can be recast in terms of the integral of the growth rate over the unstable domain: $\Gamma \doteq \int_{\gamma>0} d k \gamma_{k} \approx 2 \pi \gamma_{k_{\mathrm{f}}} k_{\mathrm{f}} \Delta k_{\mathrm{f}}$. For $k_{\mathrm{f}}<1$ one can relate $\Gamma$ to $\eta$ using $\eta=\sum_{k} \gamma_{k} k^{2}\left|\Phi_{k}\right|^{2}$ for $k \approx k_{f}$. Omitting constants of order unity (such as the Kolmogorov constant) one obtains $\eta^{1 / 3} \approx \Gamma k_{f}^{-4}$. Upon imposing the condition given by Eq. (4) around $k \approx 1$ (the most restrictive case) one finally obtains

$$
\Gamma \geq k_{f}^{4} \quad\left(k_{\rho}<1\right)
$$


for the uniform validity of the ST approximation in the whole wavenumber space. Also, one can rewrite Eq. (5) in terms of the weak turbulence parameter $\epsilon_{\mathrm{WT}}$ evaluated at $k \approx k_{\mathrm{f}}$. Assuming that $\Delta k_{\mathrm{f}} \approx k_{\mathrm{f}}$ one finds $\gamma_{k_{\mathrm{f}}} / w_{*, k_{\mathrm{f}}} \gtrsim k_{\mathrm{f}} \rho_{\mathrm{s}}$ or $\epsilon_{\mathrm{WT}} \gtrsim\left(k_{\mathrm{f}} \rho_{\mathrm{s}}\right)^{-1}$, where the original normalization length $\rho_{\mathbf{s}}^{-1}$ has been restored and $\omega_{*, k} \doteq k_{y} \rho_{\mathbf{s}} c_{\mathbf{s}} / L_{n}$.

Finally we would like to comment on the relation between the Hasegawa-Mima equation and the very similar Rossby wave (RW) equation that is employed in the modeling of atmospheric turbulence. The RW equation can be seen as the large gyroradius limit of the HM equation. Therefore only $k_{\mathrm{f}}>1$ and the $k>1$ portion of Fig. 1 must be considered. At low wavenumbers, one has $1 /\left(\tau_{k} \Delta \omega_{k}\right) \sim \epsilon^{1 / 3} k^{5 / 3}$, and large scales are always found in the weak turbulence regime. This implies the formation of zonal flows [6]. No such phenomena are expected in the Hasegawa-Mima equation.

This work was supported by U.S.D.o.E. contract number DE-AC02-76CiłO3073. One of us (M.O.) would like to thank the kind hospitality of Princeton University's Plasma Physics Laboritory where most of the work was performed.

\section{REFERENCES}

[1] B. B. Kadomtsev, Plasma Turbulence (Academic Press, New York, 1965).

[2] R. Z. Sagdeev and A. A. Galeev, Nonlinear Plasma Theory (Benjamin, New York, 1969). 
[3] R. C. Davidson, Methods in Nonlinear Plasma Theory (Academic Press, New York, 1972).

[4] A. Hasegawa and K. Mima, Phys. Rev. Lett. 39, 205 (1977).

[5] R. H. Kraichnam, Phys. Fluids 10, 1417 (1967).

[6] G. Holloway, Ann. Rev. Fluid Mech. 18, 91 (1986). 


\section{FIGURE CAPTIONS}

Figure 1. Strong-turbulence parameter $\left(\tau_{k} \Delta \omega_{k}\right)^{-1}$ as a function of wavenumber in the case of large-scale forcing ( $k_{f} \ll 1$, indicated by the dotted line).

Figure 2. Behavior of the strong-turbulence parameter in the case of small-scale forcing $\left(k_{\S} \gg 1\right)$. 


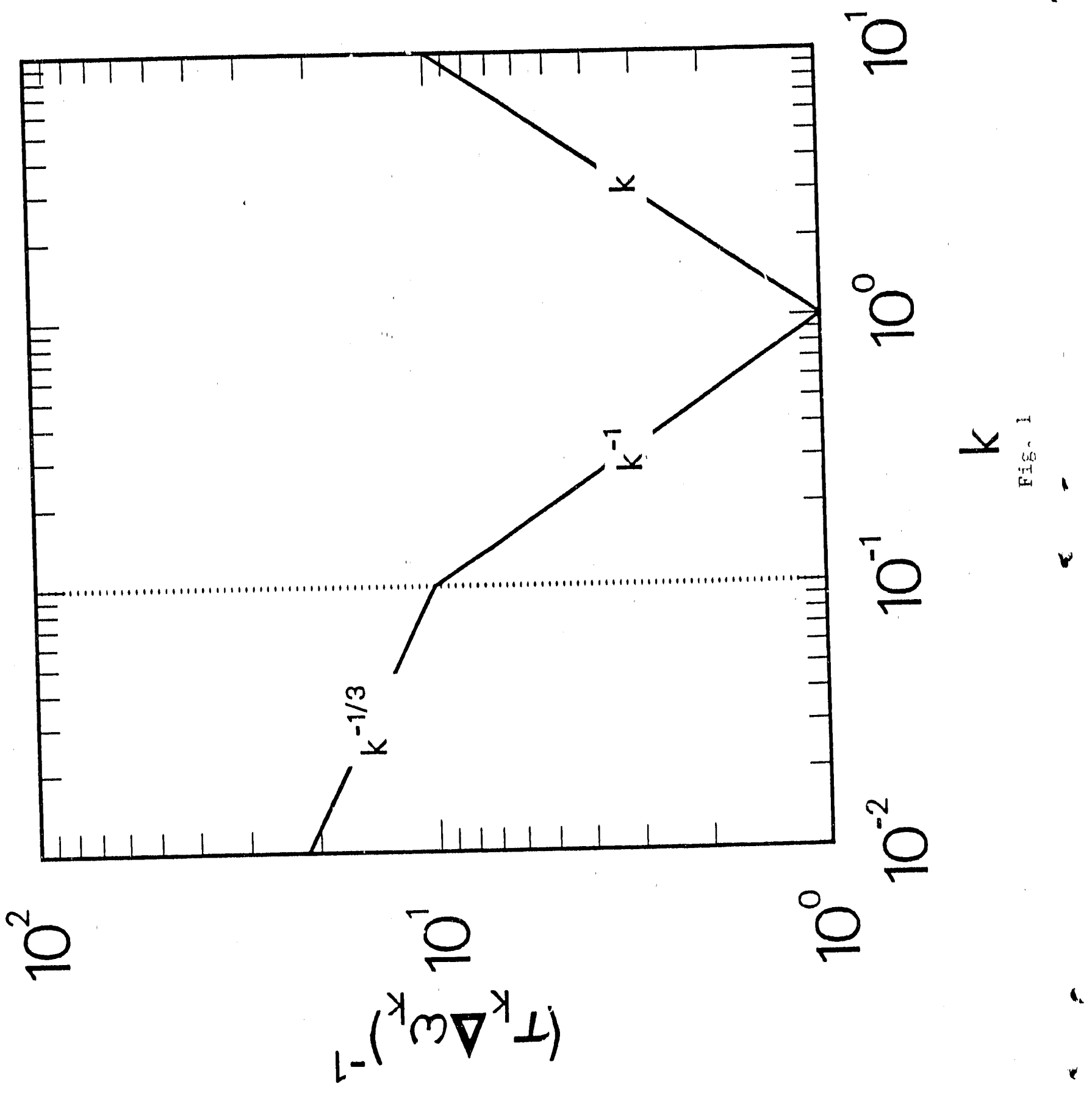




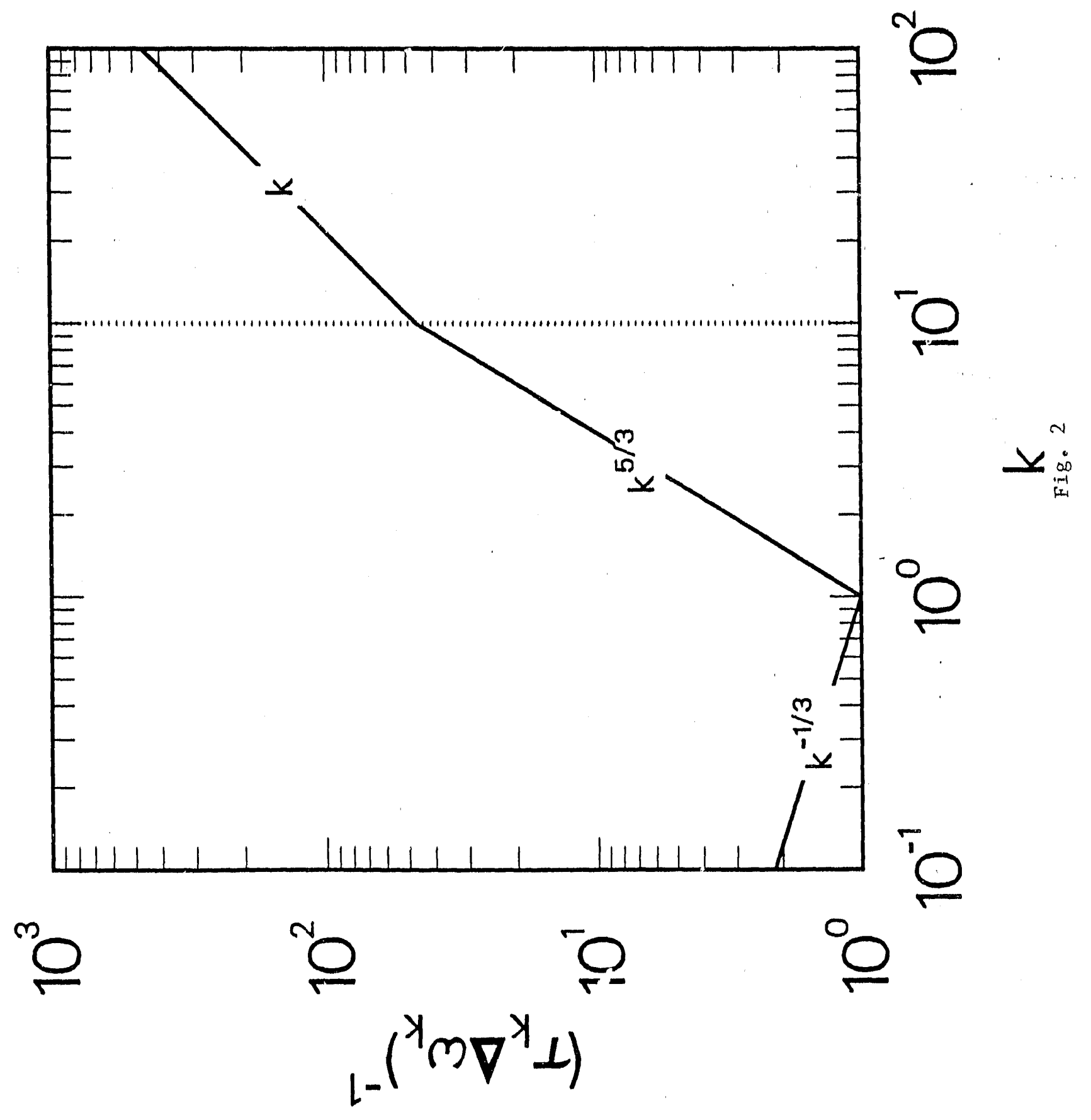




\section{EXTERNAL DISTTRIBUTION IN ADDITION TO UC-420}

Dr. F. Peoloni, Univ. of Wollongong. AUSTRALIA

Prol. M.H. Brennan, Univ of Sychoy, AUSTRALKA

Plasma Poscarch Lob., Austratien Nat. Univ., AUSTRALIA

Prof. I.R. Jones, Findors Univ, AUSTraLLA

Prol. F. Cep, Inst for Theoredical Physica, AUSTRIA

Prot. M. Hoindier, Instiut for Theoretectso Phyeik, AUSTRIA

Prot. M. Gooseons, Aetronomiech trotifuUt, BELGIUM

Ecole Roydo Antuire, Lob. do Phy. Plaemas, BELGIUM

Commicaion-Europem, DG. XII-Fucion Pros., BELGIUM

Frol. A. Bouciaus, Rikeunivenitin Gent, BELGIUM

Dr. P.H. Sakendea, Instituto Ficice, BRNZIL

Inethuts ilaciond Do Prequieas Engecide-INPE, BRUZIL

Documents Oricos, Alomic Energy of Ceneda Ld., CANADA

Dr. M.P. Bectynedi, MPB Tectrnologines, Inc., CANADA

Dr. H.M. Skeregerd, Univ. of Sackatctewen, CANADA

Prof. J. Toichmem, Univ. of Montried, CANADA

Prot. S.R. Sremiveaen, Univ. of Celpory, CANADA

Prof. T.W. Johnston, INAS-Eirergie, CANADA

Dr. R. Bowion, Contre canactien de fusion manstique, CANADA

Dr. C.R. Jemes, Univ. of Aberta, CANAOA

Dr. P. Lukta, Komendktho Uriveradita, CZECHOSLOVAKIA

Tho Librarian, Cuham Luboralory, ENGLAND

Librery, R61, Ruthertord Appletion Laboratory. ENGLAND

Mrs. S.A. Hutchineon, JET Librey, ENGLAND

Dr. S.C. Sheme, Unts. of South Pacific, FWI ISLANDS

P. Menonen, Univ. of Holeinki, FINLAND

Prof. M N. Buacece, Eoole Potyluchniqus, FRANCE

C. Mounter, Lob. do Phycique des Milioux loniede, FRANCE

J. Redat, CENCADARACHE - Bat 506, FRANCE

Prof. E. Economou, Univ. of Crow, GREECE

Ms. C. Rinni, Univ. of loomina, GREECE

Dr. T. Mud, Academy Bibliographic Ser., HONG KONG

Proprint Librery. Hungerian Acaderny of Sci., HUNGARY

Dr. B. Descupta, Saha inst of Nuctoer Phycics, INDIA

Dr. P. Kaw, Inet. tor Pleama Pocearch, INDLA

Dr. P. Rocenew, lared inst of Technobogy, ISPAEL

Librarien, Intemationd Conter for Theo Phycics, ITALY

Miss C. Do Pab, Associeziono EURATOM-ENEA, ITALY

Dr. G. Groseso, letituto di Fisican ded Plasma, ITALY

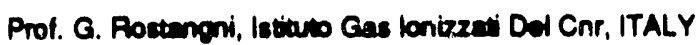

D. ب. Yenen. Toshibe Pen \& Davel Conter, JAPAN
Prot. I. Kawakemi, Hrochima Univ., JAPAN

Prof. K. Nibhikewa, Hiroehima Univ., JAPAN

Director, Jepen Alomic Enorgy Rosearch Inst, JAPAN

Prot. S. Itoh, Kyuatu Univ., LAPAN

Foeverch Into. Cr., Natoond Instit. for Fusion Scienco, JAPAN

Proi. S. Tenake, Kyob Univ., JAPAN

Librey, Kyolo Univ., JAPAN

Prof. N. Inowo, Univ. of Tohyo, LAPAN

Secretery, Pleama Saction, Electrowechnical Lab., JAPAN

S. Mori, Tectritisl Advieor, LAERI, LAPAN

Dr. O. Ming, Kumamuio inst of Tectnology, JAPAN

J. ityoon-Sook, Korea Atomic Enorgy Rosearch Inst, KOAEA

D.1. Chud, The Korsa Adv. Inst of Sod. \& Tech., KOREA

Pror. B.S. Liloy, Univ, of Weikato, NEW ZEALAND

Inst of Phyrice, Chinese Aad Sal PEOPLE'S REP. OF CHINA

Lbrey, Incl of Plaema Physics, PEOPLE'S REP. OF CHINA

Tinghua Univ. Lbrary, PEOPLE'S REPUBLIC OF CHINA

Z. Li, $S$ W. Inat Phyeics, PEOPLE'S RePUBUC OF CHINA

Prof. J.A.C. Cebre, Instituro SUperior Tecnico, PORTUGAL

Dr. O. Potrus, Al I CUzA Univ., Romania

Dr. J. do Viliers, Fution Sudies, AEC, S. AFAICA

Prof. M.A. Hewboro, Univ. of Natw, S. AFRICA

Prot. D.E. Km, Poheng inat of Sod. I Tech., SO. KOREA

Prot. C.I.E.M.A.T, Fuidon Diviaion Library, SPAIN

Dr. L Simmo, Univ, of UMEA, SWEDEN

Litrery, Royed inat of Tectnology, SWEDEN

Prot. H. Whatmecon, Chaimers Univ. of Tech., SWEDEN

Contes Phys. Dos Plasmas, Ecole Potytech, SWITZERLAND

Bibliotheck, Inst, Voor Ptarma-Fysica, THE NETHERLANDS

Asst. Prot. Dr. S. Cokir, Midds Esat Tech. Univ., TURKEY

Dr. VA. Culthith, Sad. Res. Inat. Eloctrophys.I Apparatus, USSR

Dr. D.D. Ayubv, Siberien Brench of Academy of Sa., USSA

Dr. G.A. Eleser, I.V. Kurchatov Inst, USSA

Libraien, The Ukr.SSA Academy of Scionces, USSA

Dr. LM. Kovristnnykh, Inst. of Gonerd Physics, USSR

Kemlonechungeandeos GmbH, Zentrabibliothek, W. GERMANY

Bibliothate, Inst. For Phemaloncting, W. GERMANY

Prof. K. Schinder, Ruhr-Univereit Bochum, W. GERMANY

Or. F. Wogner, (ASOEX), MaxPlenck-Inetitut, W. GERMANY

Librerien, Max-Ptanck-Instiur, W. GERMANY

Prot. R.K. Jinow, inat of Physics, YUGOSLAVIA 

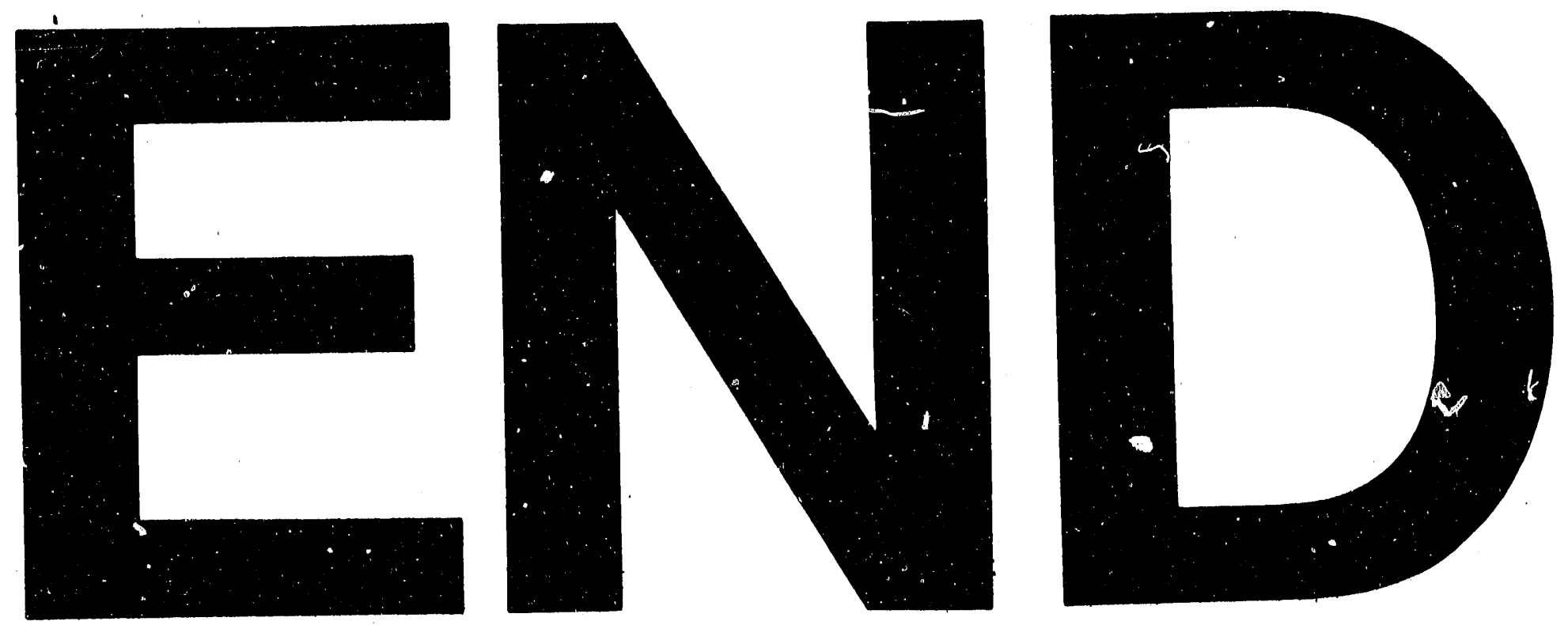

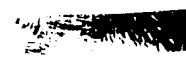

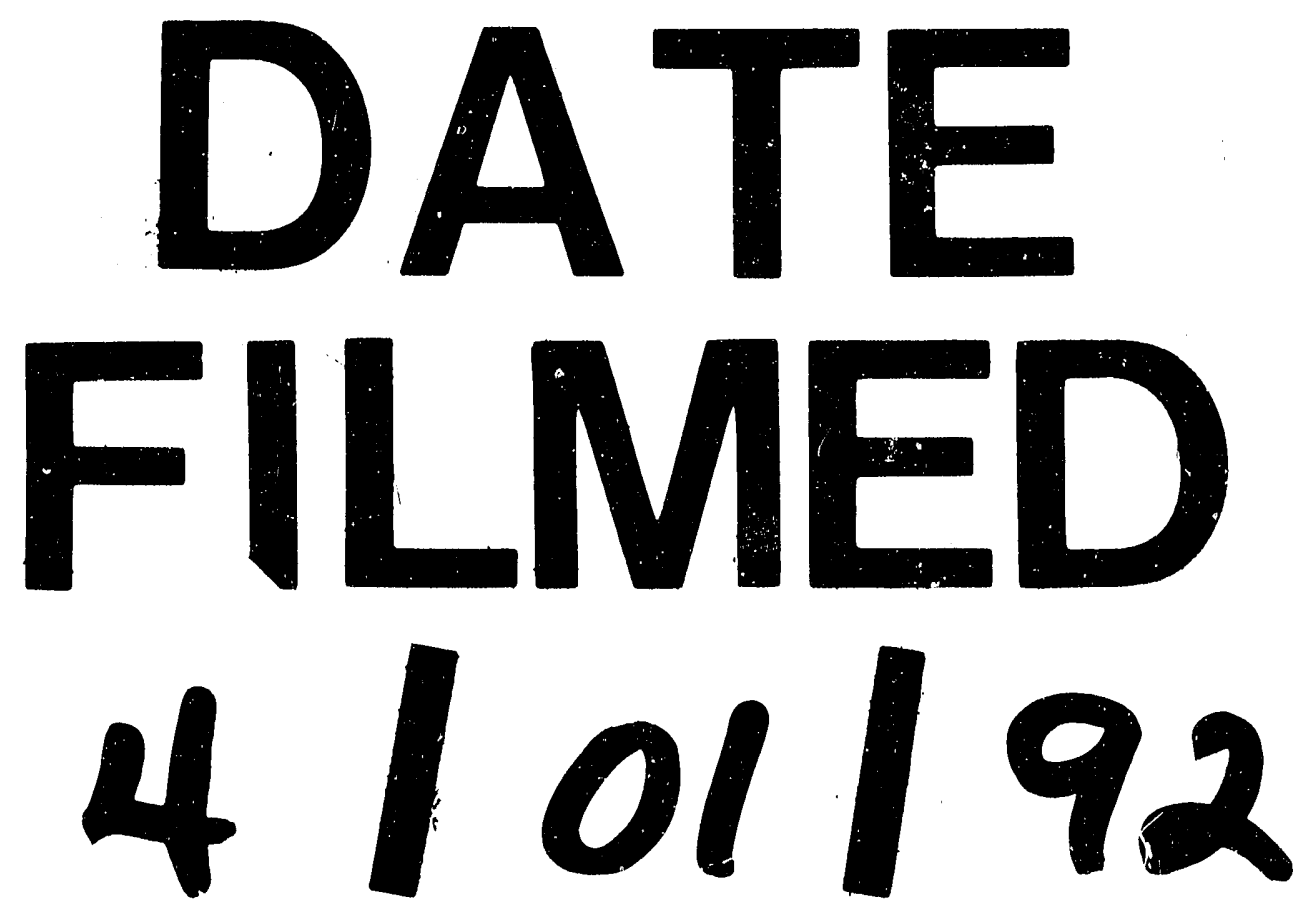

$I$ 


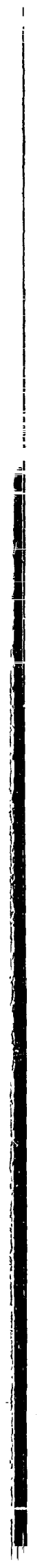

